\title{
Characteristics of Emotion and Personality in Obstructive Sleep Apnea Patients with Insomnia Symptoms: Analysis of Minnesota Multiphasic Personality Inventory
}

\author{
Ji-Hoon Lee, Won Chul Shin, Boo Suk Na, Hak Young Rhee, Hye-Yeon Choi, Sang-Beom Kim, \\ Min Ji Sung, Han A Cho, Hyun Keuk Cha \\ Department of Neurology, Kyung Hee University College of Medicine, Kyung Hee University Hospital at Gangdong, Seoul, Korea
}

\author{
불면증상이 동반된 폐쇄성 수면무호흡 환자의 정서적, 성격적 특성: 미네소타 다면적 인성검사 분석 \\ 이지훈, 신원철, 나부석, 이학영, 최혜연, 김상범, 성민지, 조한아, 차현극 \\ 경희대학교 의과대학 강동경희대학교병원 신경과학교실
}

Received November 20, 2015

Revised December 15, 2015

Accepted December 18, 2015

Address for correspondence

Won Chul Shin, MD, PhD

Department of Neurology,

Kyung Hee University

College of Medicine,

Kyung Hee University

Hospital at Gangdong,

892 Dongnam-ro, Gangdong-gu,

Seoul 05278, Korea

Tel: $+82-2-440-6166$

Fax: $+82-2-440-7262$

E-mail: shin1chul@gmail.com

Objectives: Obstructive sleep apnea-hypopnea syndrome (OSAHS) and insomnia are two of the most common sleep disorders in the general population. Because OSAHS patients with insomnia may have difficulty in adapting to the sleep breathing medical equipment, it is necessary to pay special attention to the diagnosis and treatment of comorbid insomnia. This study is to investigate the emotion and personality in OSAHS patients with insomnia complaints by using Minnesota Multiphasic Personality Inventory-2 (MMPI-2). Methods: We reviewed the results of the standardized questionnaires assessing sleep-related variables, MMPI, and polysomnographic findings of the patients diagnosed as OSAHS. Results: 145 subjects were $49.05 \pm 11.83$ years of age. The mean Respiratory Disturbance Index was $33.57 \pm 19.91$ and the mean score of Insomnia Severity Index (ISI) was 11.52 \pm 6.49 . The mean scores of the Beck Depression Inventory (BDI) and MMPI-2 were within normal ranges. We divided the patients into two groups based on the scores of the ISI, OSAHS with insomnia $(n=109)$ and OSAHS without insomnia $(n=36)$. OSAHS patients with insomnia symptoms had significantly higher scores of hypochondriasis, hysteria, psychasthenia, schizophrenia, paranoia and psychopathic deviate scales and BDI than those without insomnia. Conclusions: Our results suggest that insomnia complaints are very common in OSAHS patients and the psychological problems are more frequently found in OSAHS patients with insomnia symptom than those without it.

J Sleep Med 2015;12(2):59-63

Key Words: Obstructive sleep apnea, Insomnia, Polysomnography, Minnesota Multiphasic Personality Inventory.

\section{서 론}

폐쇄성 수면무호흡-저호흡 증후군(obstructive sleep apnea-hypopnea syndrome, OSA)은 전체 인구 중 남자에서 $4 \%$, 여자에서 $2 \%$ 의 유병률을 가지며, 수면 중 각성(arousals) 과 산소포화도 감소가 반복 되어서 깊은 잠이 방해를 받고 수

This is an Open Access article distributed under the terms of the Creative Commons Attribution Non-Commercial License (http://creativecommons.org/licenses/by-nc/3.0) which permits unrestricted non-commercial use, distribution, and reproduction in any medium, provided the original work is properly cited.
면의 연속성이 깨어짐에 따라서 수면이 양적, 질적으로 저하 되며 그 결과로 주간졸림증, 집중력과 인지 기능의 저하, 불 면증, 우울증, 주간 두통 등을 초래할 수 있다. ${ }^{1-4}$

일반적으로 수면호흡장애가 있는 환자의 40 50\%가 불면 증을 호소하며,,$^{5-7}$ 수면유지의 어려움이 OSA 환자에서 나타 나는 불면증의 가장 흔한 형태이다.,8 수면호흡장애로 인해 수면 중 각성이 반복되어 수면이 분절화되면 결국 이의 유지 가 어려워지기 때문에 OSA 환자들이 불면증상을 호소하는 것으로 생각된다. 불면증상이 동반된 OSA 환자들은 지속적 
양압환기(continuous positive airway pressure, $\mathrm{CPAP}$ )에 대 한 환자의 순응도가 불면증상이 동반되지 않은 OSA 환자들 에 비해서 떨어질 수 있으며,, 10 또한 불면증으로만 진단되어 수면제를 복용하게 되면 OSA가 악화될 수 있어 주의가 필 요하기 때문에, 불면증상이 동반된 OSA 환자들의 양상을 이해하는 것이 중요하다.

본 연구는 불면증상이 동반된 폐쇄성 수면무호흡-저호흡 증후군 환자들을 대상으로 미네소타 다면적 인성검사(Minnesota Multiphasic Personality Inventory-2, MMPI-2)와 벡우울증척도(Beck Depression Inventory, BDI) 등의 신경심 리검사와 수면다원검사를 이용하여, 이들 환자들의 수면양 상과 심리검사적 특성을 알아보고자 하였다.

\section{방 법}

\section{대 상}

본 연구는 2011년 1월 1일부터 2012년 12월 31일까지 강 동경희대학교병원 수면센터에서 주간졸음증, 코골이, 수면 중 숨이 막히거나 헐떡임, 피로감, 집중력 저하 등의 임상증 상을 호소하여 수면다원검사를 시행 받은 환자 중, 수면다원 검사에서 $\mathrm{OSA}$ 로 확진된 환자들을 대상으로 하였다. 나이가 20세 미만이거나 연구에서 요구하는 사항들의 수행에 지장 을 줄 수 있는 정신 지체, 치매 혹은 인지 기능에 영향을 줄 수 있는 약물을 복용하고 있는 경우, 이전에 우울증을 진단받 은 경우는 제외하였다.

\section{방 법}

\section{수면다원검사}

수면다원검사(Grass Technology, Warwick, RI, USA)는 뇌 파(electroencephalogram), 안구운동(electrooculogram) 및 턱과 사지의 근전도(electromyogram), 입과 코를 통한 공기 흐름(thermister, nasal pressure transducer), 흥부와 복부의 움직임, 산소포화도 등을 측정하였다. 무호흡은 호흡운동이 유지된 상태에서 호흡이 10초 이상 완전히 멈춘 경우로 정 의하였고, 저호흡은 10 초 이상 지속되면서 호흡량 진폭이 기 준에 비해 $30 \%$ 의 감소를 보이면서 이와 관련된 $4 \%$ 이상의
산소포화도 감소가 있는 경우로 정의하였다. 그 외 수면잠복 시간, 수면효율, 각성지수(arousal index), 무호흡-저호흡지 수(apnea-hypopnea index, AHI), 호흡장애지수(respiratorydistress index, RDI), 최저 산소포화도, 주기적사지운동지수 및 수면 구조를 산출하였다.

\section{수면설문지}

주간수면과다의 평가를 위한 한국판 엡워스졸음척도(Epworth Sleepiness Scale, ESS), 한국판 스텐포드졸음척도 (Stanford Sleepiness Scale, SSS), 한국판 불면증심각도지수 (Insomnia Severity Index, ISI), 한국판 피츠버그수면질지수 (Pittsburgh Sleep Quality Index, PSQI) 등이 포함되었다. ${ }^{11-15}$ 이외에 기본적인 인구학적 특성 및 다른 질환의 동반 여부 와 약물력 여부를 조사하였다.

\section{신경심리검사}

신경심리검사로는 우울증 정도를 평가하기 위해 한국판 벡 우울증척도(BDI)와 인성 및 정서를 평가하는 한국판 미네소 타 다면적 인성검사(MMPI-2)를 시행하였다. ${ }^{16-18}$

\section{절차 통계 분석}

본 연구의 통계적 분석과정은 Statistical Package for the Social Science 18.0(SPSS Inc., Chicago, IL, USA)을 이용하 여 분석하였다. 불면증이 동반된 폐쇄성 수면무호흡-저호흡 증후군과 불면증이 동반되지 않은 폐쇄성 수면무호흡-저호 흡 증후군으로 각각 구분하였고, 두 집단의 수면다원검사적 패턴과 심리검사적 특징을 확인하기 위하여 독립표본 t-test 를 실시하였다.

\section{결 과}

\section{일반적 특성}

연구기간 동안 폐쇄성 수면무호흡-저호흡 증후군이 임상 적으로 의심되어 수면다원검사를 시행받은 환자는 총 226명 이었고, 이 중 수면다원검사에서 $\mathrm{AHI}$ 가 $5.0 / \mathrm{h}$ 이상이면서 모든 수면 설문지와 벡우울증척도 및 MMPI-2를 시행한 환 자는 145 명이었다. 145 명의 평균 나이는 $49.05 \pm 11.83$ 세였고,

Table 1. Demographics of obstructive sleep apnea patients with and without insomnia symptoms

\begin{tabular}{lcccc}
\hline \multicolumn{1}{c}{ Characteristics } & Total OSAHS $(\mathrm{n}=145)$ & OSAHS with insomnia $(\mathrm{n}=81)$ & OSAHS without insomnia $(\mathrm{n}=64)$ & $p$ \\
\hline Sex (M:F) & $55: 4$ & $36: 3$ & $19: 1$ & - \\
Age (years) & $49.05 \pm 11.83$ & $48.46 \pm 1.92$ & $50.20 \pm 2.62$ & 0.598 \\
Body mass index & $26.91 \pm 2.94$ & $26.93 \pm 3.07$ & $26.89 \pm 2.71$ & 0.965 \\
\hline
\end{tabular}

Values are expressed as means \pm SD. OSAHS: obstructive sleep apnea-hypopnea syndrome 
평균 체질량지수는 $26.91 \pm 2.94$ 였으며, ISI의 평균 점수는 $11.53 \pm 6.49$ 였다(Table 1). 전체 환자들을 ISI 점수를 기준으 로 8점 이상인 환자들을 OSA+Insomnia군, 8점 미만인 환자 들을 OSA-Insomnia군으로 구분하였다. OSA+Insomnia군

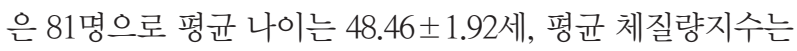
$26.93 \pm 3.07$ 이었으며, OSA-Insomnia군은 64명으로 평균

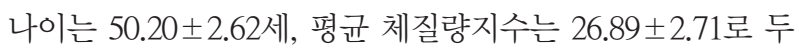
군 사이의 유의한 차이는 관찰되지 않았다.

\section{수면 설문지 분석(Table 2)}

전체 대상자의 $\mathrm{SSS}$ 의 평균 점수는 $3.16 \pm 1.37$ 점, $\mathrm{ESS}$ 의 평균 점수는 7.66 \pm 4.47점이었고, PSQI 평균 점수는 $13.36 \pm$ 6.75점이었으며, OSA+Insomnia군은 OSA-Insomnia군에 비해 $\operatorname{SSS}(3.34 \pm 1.56$ vs. $2.65 \pm 0.75, p=0.037), \operatorname{ESS}(8.56 \pm$ 4.78 vs. $5.90 \pm 3.24, p=0.029)$, PSQI(15.80 \pm 6.67 vs. $8.95 \pm$ $4.24, p<0.001)$ 등의 모든 점수가 통계적으로 의미 있게 높
았다(Table 2).

\section{수면다원검사 분석(Table 3)}

대상 환자의 총 수면시간은 327.52분이었고, 이 중 1기 비 렘수면은 $30.83 \%, 2$ 기 비렘수면은 $39.50 \%, 3$ 기 비렘수면은 $14.41 \%$, 렘수면(rapid eye movement sleep)은 $17.51 \%$ 였으 며, 입면후각성(wakefulness after sleep onset, WASO)은 $17.01 \%$, 수면효율(sleep efficacy)은 80.92\%였다(Table 3). 또 한 평균 $\mathrm{AHI}$ 는 $27.85 \pm 20.79 / \mathrm{h}, \mathrm{RDI}$ 는 $33.57 \pm 19.92 / \mathrm{h}$ 였 고, 최저 산소포화도는 80.58 $\pm 9.17 \%$ 였다. OSA+Insomnia 군과 OSA-Insomnia군 간에 총 수면시간, 비렘수면, 렘수면, $\mathrm{WASO}$, 수면효율, $\mathrm{AHI}, \mathrm{RDI}$, 최저 산소포화도 등의 모든 수 면다원검사 지표의 유의한 차이는 관찰되지 않았다.

\section{우울증척도와 MMPI-2 분석}

$\mathrm{K}$-BDI 점수는, OSA+Insomnia군이 OSA-Insomnia군에

Table 2. Questionnaire findings of obstructive sleep apnea patients with and without insomnia symptoms

\begin{tabular}{lcccc}
\hline Variables & Total OSAHS & OSAHS with insomnia & OSAHS without insomnia & $p$ \\
\hline ISI & $11.53 \pm 6.49$ & $15.10 \pm 4.83$ & $4.55 \pm 2.11$ & $<0.001^{*}$ \\
SSS & $3.16 \pm 1.37$ & $3.44 \pm 1.56$ & $2.65 \pm 0.75$ & $0.037^{*}$ \\
ESS & $7.66 \pm 4.47$ & $8.56 \pm 4.78$ & $5.90 \pm 3.24$ & $0.029^{*}$ \\
PSQI & $13.36 \pm 6.75$ & $15.80 \pm 6.67$ & $8.95 \pm 4.27$ & $<0.001^{*}$ \\
K-BDI & $11.39 \pm 9.19$ & $14.41 \pm 9.31$ & $5.50 \pm 5.42$ & $<0.001^{*}$ \\
\hline
\end{tabular}

Values are expressed as means \pm SD. ${ }^{*} p<0.05$. OSAHS: obstructive sleep apnea-hypopnea syndrome, SSS: Stanford Sleepiness Scale, ESS: Epworth Sleepiness Scale, PSQI: Pittsburgh Sleep Quality Index, ISI: Insomnia Severity Index, K-BDI: Korean version of Beck Depression Inventory

Table 3. Polysomnographic findings of obstructive sleep apnea patients with and without insomnia symptoms

\begin{tabular}{lcccc}
\hline \multicolumn{1}{c}{ Variables } & Total OSAHS & OSAHS with insomnia & OSAHS without insomnia & $p$ \\
\hline Hypnogram & & & & \\
TST (min) & $327.52 \pm 52.27$ & $328.73 \pm 53.26$ & $325.15 \pm 51.56$ & 0.806 \\
S1 sleep (\%) & $30.83 \pm 18.21$ & $29.09 \pm 16.45$ & $34.23 \pm 21.29$ & 0.309 \\
S2 sleep (\%) & $39.50 \pm 20.41$ & $39.15 \pm 16.97$ & $40.20 \pm 26.36$ & 0.854 \\
S3+S4 sleep (\%) & $14.41 \pm 16.37$ & $15.14 \pm 19.10$ & $12.99 \pm 9.21$ & 0.637 \\
REM sleep (\%) & $17.51 \pm 9.29$ & $17.95 \pm 8.57$ & $16.66 \pm 10.74$ & 0.618 \\
WASO (\%) & $17.01 \pm 11.28$ & $16.90 \pm 11.93$ & $17.24 \pm 10.19$ & 0.913 \\
SE (\%) & $80.92 \pm 11.60$ & $81.17 \pm 12.12$ & $80.45 \pm 10.80$ & 0.823 \\
Respiratory events & & & & 0.315 \\
Apnea index & $68.19 \pm 105.54$ & $67.97 \pm 94.24$ & $105.50 \pm 69.14$ & 0.192 \\
Hypopnea index & $90.03 \pm 64.87$ & $82.10 \pm 61.99$ & $29.05 \pm 18.73$ & 0.754 \\
AHI & $27.85 \pm 20.79$ & $27.24 \pm 21.98$ & $33.15 \pm 18.19$ & 0.909 \\
RDI & $33.57 \pm 19.92$ & $33.78 \pm 20.97$ & $81.42 \pm 11.06$ & 0.621 \\
Lowest SaO 2 & $80.58 \pm 9.17$ & $80.16 \pm 8.16$ & & \\
\hline
\end{tabular}

Values are expressed as means \pm SD. OSAHS: obstructive sleep apnea-hypopnea syndrome, TST: total sleep time, S1: stage 1, S2: stage 2, S3: stage 3, S4: stage 4, REM: rapid eye movement, WASO: wakefulness after sleep onset, SE: sleep efficacy, AHI: apnea hypopnea index, $\mathrm{RDI}$ : respiratory disturbance index, $\mathrm{SaO}_{2}$ : blood oxygen saturation 
비해 통계적으로 유의하게 높았다(14.41 \pm 9.31 vs. $5.50 \pm 5.42$, $p<0.001$ )(Table 2).

MMPI-2를 작성한 전체 환자 중 무응답 항목이 30문항 이 상이거나 타당도 척도 또한 T점수 70점 이상으로 상승되어 응답의 신뢰도나 타당도의 문제가 있어 보이는 12 명은 제외 한 133 명만 분석하였다. 전체 대상자의 MMPI-2의 임상 척 도 중 건강염려증은 전체 평균은 $55.59 \pm 10.55$, 우울증은 $55.68 \pm 12.12$, 히스테리는 $54.59 \pm 10.55$, 반사회성은 $49.22 \pm$ 8.86 , 남성성-여성성은 $51.37 \pm 10.88$, 편집증은 $48.31 \pm 7.54$, 강박증은 $53.15 \pm 10.71$, 정신분열증은 $49.81 \pm 8.15$, 경조증은 $48.08 \pm 8.96$, 내향성은 $54.27 \pm 10.97$ 이었다(Table 4). OSA+ Insomnia군은 OSA-Insomnia군에 비해 MMPI-2의 임상 척도 중, 건강염려증( $57.67 \pm 10.43$ vs. $48.60 \pm 8.07, p=0.001)$, 히스테리(55.64 \pm 10.12 vs. $49.65 \pm 8.71, p=0.028)$, 반사회성 ( $50.90 \pm 9.05$ vs. $45.95 \pm 7.65, p=0.041)$, 편집증( $49.85 \pm 7.73$ vs. $45.30 \pm 6.31, p=0.027)$, 강박증 $(56.23 \pm 9.44$ vs. $47.15 \pm 10.71$, $p=0.001)$, 정신분열증 $(51.59 \pm 7.75$ vs. $46.35 \pm 7.99, p=0.018)$ 의 항목 점수가 유의하게 높았다. 우울증( $57.35 \pm 11.46$ vs. $52.40 \pm 12.99, p=0.138)$, 남성성-여성성(52.18 \pm 9.97 vs. $49.80 \pm 12.60, p=0.431)$, 경조증 $(49.38 \pm 9.11$ vs. $45.55 \pm 8.28$, $p=0.120)$, 내향성(55.87 \pm 10.81 vs. $51.15 \pm 10.87, p=0.119)$ 은 양 군 간에 차이가 없었다.

\section{고 찰}

본 연구에서는 전체 대상 환자들 중 불면증상을 호소한 환자는 $60.7 \%$ 로, OSA 환자들에게 있어서 불면증상의 빈도 를 분석했던 기존 연구들의 39 58\%보다 다소 높은 수치이 다. ${ }^{6,719}$ 본 연구는 단일 수면센터에 내원한 환자들을 대상으 로 시행한 연구로, 우리나라 전체 OSA 환자들의 특성이라
할 수 없으며, 향후 이에 대한 추가적인 연구가 필요하다. $\mathrm{OSA}+\mathrm{Insomnia}$ 환자군은 SSS, ESS, PSQI의 점수가 OSAInsomnia 환자군에 비해 의미 있게 점수가 높아서 주간졸림 및 수면의 질 저하를 보다 많이 호소하였다. 불면증이 동반 된 군과 동반되지 않은 두 군 간의 수면다원검사 소견을 비 교하였을 때 총 수면시간, $\mathrm{WASO}$, 수면효율, $\mathrm{AHI}, \mathrm{RDI}$, 각 성, 수면구조 등의 개관적인 지표상의 의미 있는 차이가 관 찰되지 않았다. 이는 이전에 OSA와 불면증의 상관 관계에 관한 몇몇 연구에서 환자가 호소하는 불면 증상과 수면다원 검사의 소견 간에 의미 있는 상관 관계가 관찰되지 않았던 점과 일치하는 결과이다. ${ }^{5-7,19}$ 따라서 OSA+Insomnia 환자들 은 OSA-Insomnia 환자들보다 주관적인 수면의 질 저하를 호소할 수 있으며, 수면호흡장애 이외의 다른 요인이 이러한 주관적인 수면의 질 저하를 일으킬 수 있음을 시사한다.

OSA+Insomnia 환자들에서, K-BDI와 MMPI-2에서 불 안과 건강염려증, 히스테리, 반사회성, 편집성, 강박증 및 정 신분열증 척도 점수가 유의하게 높았다. 이러한 양상은 전체 인구 집단을 대상으로 한 불면증 환자의 특징과 유사하여 OSA+Insomnia 환자군에서만의 특징적인 소견이라고 보기 는 어려우며, ${ }^{20-23}$ 도리어 OSA와 불면증이 동반된 경우가 불 면증과 연관된 불안 등의 감정 상태 및 정신적인 문제들을 보다 많이 가지고 있으며, 이것이 앞서 기술한 수면호흡장애 의 심각도와 상관없이 주관적인 수면의 질을 떨어뜨리는 요 인일 가능성을 보여준다. 그러나 불면증을 구분하지 않은 $\mathrm{OSA}$ 환자들을 대상으로 시행한 다른 연구에서도 MMPI에 서 건강염려증 및 반사회성 척도가 유의하게 높게 확인되었 고, ${ }^{24} \mathrm{CPAP}$ 치료와 함께 OSA가 호전된 환자에서 이러한 정 신사회학적 상태의 호전도 함께 관찰되었다는 이전 보고는 이러한 감정상태 및 정신적인 문제들이 OSA의 원인일 뿐만 아니라 결과일 수도 있다는 점을 시사하기 때문에 인과관계

Table 4. Comparison of Beck Depression Inventory and Minnesota Multiphasic Personality Inventory-2 in obstructive sleep apnea patients with and without insomnia symptoms

\begin{tabular}{lcccc}
\hline \multicolumn{1}{c}{ Variables } & Total OSAHS $(\mathrm{n}=133)$ & OSAHS with insomnia $(\mathrm{n}=72)$ & OSAHS without insomnia $(\mathrm{n}=61)$ & $p$ \\
\hline Hypochondriasis & $54.59 \pm 10.55$ & $57.67 \pm 10.43$ & $48.60 \pm 8.07$ & $0.001^{*}$ \\
Depression & $55.68 \pm 12.12$ & $57.35 \pm 11.46$ & $52.40 \pm 12.99$ & 0.138 \\
Hysteria & $53.61 \pm 10.01$ & $55.64 \pm 10.12$ & $49.65 \pm 8.71$ & $0.028^{*}$ \\
Psychopathic deviate & $49.22 \pm 8.86$ & $50.90 \pm 9.05$ & $45.95 \pm 7.65$ & $0.041^{*}$ \\
Masculinity-feminity & $51.37 \pm 10.88$ & $52.18 \pm 9.97$ & $49.80 \pm 12.60$ & 0.431 \\
Paranoia & $48.31 \pm 7.54$ & $49.85 \pm 7.73$ & $45.30 \pm 6.31$ & $0.027^{*}$ \\
Psychasthenia & $53.15 \pm 10.71$ & $56.23 \pm 9.44$ & $47.15 \pm 10.71$ & $0.001^{*}$ \\
Schizophrenia & $49.81 \pm 8.15$ & $51.59 \pm 7.75$ & $46.35 \pm 7.99$ & $0.018^{*}$ \\
Hypomania & $48.08 \pm 8.96$ & $49.38 \pm 9.11$ & $45.55 \pm 8.28$ & 0.120 \\
Social introversion & $54.27 \pm 10.97$ & $55.87 \pm 10.81$ & $51.15 \pm 10.87$ & 0.119 \\
\hline
\end{tabular}

Values are expressed as means \pm SD. ${ }^{*} p<0.05$. OSAHS: obstructive sleep apnea-hypopnea syndrome 
에 대한 해석에 주의가 필요하다. ${ }^{25}$

불면증이 동반된 OSA 환자들은 가장 효과적인 치료인 $\mathrm{CPAP}$ 치료의 순응도가 낮아질 수 있기 때문에, 불면증이 동 반되어 있는지의 여부를 확인하는 것은 매우 중요하다. ${ }^{9,10,26-29}$ 이는 본 연구의 결과에서와 같이 불면증이 동반된 OSA 환 자들은 정서와 감정문제들을 흔히 가지고 있는데, 이로 인해 $\mathrm{CPAP}$ 마스크와 기계착용에 대해 심한 불편감과 거부감을 느껴 빈번한 수면각성이 반복적으로 일어나 CPAP에 대한 순응도가 떨어지게 될 수 있다. 따라서 OSA 환자에서 불면증 이 동반되어 있는지를 확인하는 것은 폐쇄성 수면호흡장애 를 치료하는 데 있어서 매우 중요할 것으로 생각되며, 불면증 의 동반 유무를 미리 확인하고 이에 대한 평가와 치료를 통 해 정신-감정장애를 조절한다면 환자의 치료 순응도를 높이 는 데 도움이 될 수 있을 것이다. 더욱이 동반된 불면증의 유 무를 평가하는 데 있어서 두 군 간에 체질량지수나 수면다원 검사 소견의 차이가 나지 않으므로 수면다원검사 이전에 수 면질환병력, 내과질환병력, 신경계질환병력, 정신심리병력 등 의 병력청취가 진단에 매우 중요하다고 하겠다.

결론적으로 본 연구를 통해 폐쇄성 수면무호흡-저호흡 증후군 환자들에게 있어서 불면증이 흔한 증상임을 확인할 수 있었으며, 또한 불면증이 동반된 폐쇄성 수면무호흡-저 호흡 증후군 환자들은 정서와 감정적인 문제를 갖고 있어 주관적인 수면의 질 저하를 호소할 수 있음을 알 수 있었다. 따라서 OSA 환자들을 진단하고 치료할 때, 수면호흡장애에 대한 평가뿐만 아니라 불면증의 동반 여부 및 이에 대한 평 가와 치료를 위한 충분한 병력청취 및 신경심리검사가 같이 이루어져야 할 것으로 사료된다.

\section{REFERENCES}

1. Malhotra A, White DP. Obstructive sleep apnoea. Lancet 2002;360: 237-245.

2. Young T, Peppard PE, Gottlieb DJ. Epidemiology of obstructive sleep apnea: a population health perspective. Am J Respir Crit Care Med 2002;165:1217-1239.

3. Chervin RD. Sleepiness, fatigue, tiredness, and lack of energy in obstructive sleep apnea. Chest 2000;118:372-379.

4. Aloia MS, Arnedt JT, Smith L, Skrekas J, Stanchina M, Millman RP. Examining the construct of depression in obstructive sleep apnea syndrome. Sleep Med 2005;6:115-121.

5. Chung KF. Insomnia subtypes and their relationships to daytime sleepiness in patients with obstructive sleep apnea. Respiration 2005;72:460-465.

6. Krakow B, Melendrez D, Ferreira E, et al. Prevalence of insomnia symptoms in patients with sleep-disordered breathing. Chest 2001; 120:1923-1929.

7. Smith S, Sullivan K, Hopkins W, Douglas J. Frequency of insomnia report in patients with obstructive sleep apnoea hypopnea syndrome
(OSAHS). Sleep Med 2004;5:449-456.

8. Chung KF. Relationships between insomnia and sleep-disordered breathing. Chest 2003;123:310-311; author reply 311-313.

9. Glidewell RN, Renn BN, Roby E, Orr WC. Predictors and patterns of insomnia symptoms in OSA before and after PAP therapy. Sleep Med 2014;15:899-905.

10. Björnsdóttir E, Janson C, Sigurdsson JF, et al. Symptoms of insomnia among patients with obstructive sleep apnea before and after two years of positive airway pressure treatment. Sleep 2013;36:1901-1909.

11. Johns MW. A new method for measuring daytime sleepiness: the Epworth sleepiness scale. Sleep 1991;14:540-545.

12. Seo WS, Son HI, Koo BH, et al. Clinical Features of Korean Obstructive Sleep Apnea Syndrome and Usefulness of Korean Version of Epworth Sleepiness Scale. J Korean Soc Biol Ther Psychiatry 2005;11:150-157.

13. Glenville M, Broughton R. Reliability of the Stanford Sleepiness Scale compared to short duration performance tests and the Wilkinson Auditory Vigilance Task. Adv Biosci 1978;21:235-244.

14. Cho YW, Song ML, Morin CM. Validation of a Korean version of the insomnia severity index. J Clin Neurol 2014;10:210-215.

15. Sohn SI, Kim do H, Lee MY, Cho YW. The reliability and validity of the Korean version of the Pittsburgh Sleep Quality Index. Sleep Breath 2012;16:803-812.

16. Beck AT, Ward CH, Mendelson M, Mock J, Erbaugh J. An inventory for measuring depression. Arch Gen Psychiatry 1961;4:561-571.

17. Lee YH, Song JY. A study of the reliability and the validity of the BDI, SDS, and MMPI-D scales. Korean J Clin Psychol 1991;10:98-113.

18. Kim JS, Han KH, Lim JY, Lee JH, Min BB, Moon KJ. Korean MMPI-2 user manual. Seoul: Maumsarang, 2005.

19. Krell SB, Kapur VK. Insomnia complaints in patients evaluated for obstructive sleep apnea. Sleep Breath 2005;9:104-110.

20. Tsushima WT, Ingolfsdottir E. MMPI-2 scores of patients with insomnia. Psychol Rep 2004;94:267-272.

21. Aikens JE, Caruana-Montaldo B, Vanable PA, Tadimeti L, Mendelson WB. MMPI correlates of sleep and respiratory disturbance in obstructive sleep apnea. Sleep 1999;22:362-369.

22. Kalogjera-Sackellares D, Cartwright RD. Comparison of MMPI profiles in medically and psychologically based insomnias. Psychiatry Res 1997;70:49-56.

23. Ancoli-Israel S, Roth T. Characteristics of insomnia in the United States: results of the 1991 National Sleep Foundation Survey. I. Sleep 1999;22 Suppl 2:S347-S353.

24. Ekici A, Ekici M, Oğuztürk O, Karaboğa I, Cimen D, Senturk E. Personality profiles in patients with obstructive sleep apnea. Sleep Breath 2013;17:305-310.

25. Ramos Platón MJ, Espinar Sierra J. Changes in psychopathological symptoms in sleep apnea patients after treatment with nasal continuous positive airway pressure. Int J Neurosci 1992;62:173-195.

26. Stepnowsky CJ Jr, Bardwell WA, Moore PJ, Ancoli-Israel S, Dimsdale JE. Psychologic correlates of compliance with continuous positive airway pressure. Sleep 2002;25:758-762.

27. Wild MR, Engleman HM, Douglas NJ, Espie CA. Can psychological factors help us to determine adherence to CPAP? A prospective study. Eur Respir J 2004;24:461-465.

28. Wells RD, Freedland KE, Carney RM, Duntley SP, Stepanski EJ. Adherence, reports of benefits, and depression among patients treated with continuous positive airway pressure. Psychosom Med 2007;69:449-454.

29. Lee SM, Lee YJ, Kim JH. Common Side Effects and Compliance with Nasal Continuous Positive Airway Pressure in Korean OSA patients: Short-term Follow Up. J Korean Sleep Res Soc 2010;7:1-7. 